\title{
From neoclassical theory to mainstream modelling: fifty years of moral hazard in perspective.
}

\author{
(To appear in the volume: What is this 'school' called neoclassical economics? \\ Debating the issues, edited by Jamie Morgan)
}

\author{
J.S. Latsis and C. Repapis
}

\section{Introduction}

Tony Lawson asks why and under what circumstances we should use the term 'neoclassical' to refer to a specific school of economics. His answer is both nuanced and strategic. It is nuanced in the sense that, though Lawson believes that a conception of neoclassicism can be salvaged, that conception differs significantly from accounts defended by neoclassical economists themselves and by prominent historians of economic thought. It is strategic in the sense that, following a careful reconstruction of how Veblen's original conception of neoclassicism might be extended to strands of modern economics, Lawson eventually suggests that the term should be abandoned.

We begin with what we see as a major but under-emphasised contribution of Lawson's paper: rendering the distinction between neoclassical and mainstream economics more precise. As Lawson points out, the frequent elision of the older conception of neoclassicism and the modern mainstream by historians, philosophers and practicing economists has been intellectually stultifying; supressing debate and neutralising effective critique. In Section 1, we briefly present Lawson's analysis and contextualise it. We then go on to show that Lawson's apparent rejection of the neoclassical label may not be desirable in the context of research in the history of economic thought. Whilst we agree that a reformulated conception of neoclassical economics may be of limited use for understanding the state of modern economics, it can nevertheless serve as a powerful analytical tool when analysing historical debates. It provides us with a way to address an important historiographical problem in the evolution of $20^{\text {th }}$ century economic thought. This is to chart the transformation of economics from the pre-WWII neoclassical theory to modern mainstream modelling. While this is a complex and multi-layered problem, we use Lawson's distinction to investigate a particular transformation that relates to healthcare economics: the introduction and subsequent use of the concept of 'moral hazard' by economists.

As recent policy debates have shown, models of moral hazard are now at the core of the discipline of economics to such an extent that they have been utilised as analytical and policy tools in a wide variety of contexts (Latsis and Repapis, 2014). In Section 2, we trace the humble origins of moral hazard as a peripheral element of Kenneth Arrow's American Economic Review article 'Uncertainty and the welfare economics of medical care' (Arrow, 1963). This seminal article is widely regarded to be a key contribution to neoclassical economics because it effectively launched health economics as a field, and is also considered to be one of the pioneering contributions to the literature on informational asymmetries. Our discussion of Arrow (1963) reveals the tension between ontology and method that is characteristic of Lawson's use of the term 'neoclassical'. More importantly, however, by fitting Arrow's contribution into Lawson's mould, we gain a new perspective on and a better 
understanding of the debates surrounding the paper, its initial reception and it's subsequent use.

In Sections 3 and 4, we highlight tensions that arose almost immediately between Arrow, the architect of what quickly came to be seen as a new framework for analysing healthcare, and those who wished to appropriate his insights to develop various subfields within economics. Differences in political ideology and theoretical assumptions are apparent in several cases, but the most pervasive and the least noticed tension can be identified at a deeper level. Whilst Arrow struggled with the mismatch between ontology and method that is typical of neoclassical theorising, most critics were blind to these concerns. Our analysis suggests that Arrow is a neoclassical in Lawson's sense, however many of his interlocutors -- both followers and critics -- are not. Framing the debate in terms of the tension between ontology and methodology that is characteristic of Lawson's version of neoclassicism provides a new perspective on the remarkable intellectual trajectory of one of Arrow's key contributions to economic theory.

\section{Ontology and method in the neoclassical school}

Lawson starts with two puzzles that arise from the current use of the term 'neoclassical' in economics: first that it is used in a vague and undisciplined way by both critics and supporters; and second that this usage undermines clear discussion and effective critique. These two observations point to the same problem, which is that because it is difficult to define neoclassicism in a non-controversial and widely accepted manner, it is unclear which authors or contributions can be called neoclassical in a meaningful way. The critique of neoclassical economics can thus be said to miss its target because the definitions used by critics are at odds with each other, or with the definition used by defenders, or the self-perception of the economists the term intends to describe. In addition, continuing debates about the 'true nature' of neoclassicism can deflect attention away from the failings of modern economics, adding further confusion to the use of the term 'neoclassical'. Lawson's article seeks to address the interpretative puzzle by showing that a coherent conception of neoclassicism can be reconstructed based on Veblen's early definition of the term. He does not claim to be able to resolve the second puzzle, arguing that the terminology of neoclassicism should be abandoned (at least insofar as it relates to current debates).

Lawson's definition of neoclassical economics draws heavily on Veblen, who was responsible for coining the term at the turn of the $20^{\text {th }}$ century. As Lawson (2013:967969) explains, Veblen's neologism was carefully chosen to reflect both the influence of the modern 'evolutionary' approach (neo) and continuity with the older 'taxonomic' approach (classical). He also recognised the tension that this juxtaposition of old and new had on the key neoclassical contributions of the late $19^{\text {th }}$ century by Alfred Marshall and John Neville Keynes.

“... I am suggesting that Veblen introduces the term "neoclassical to distinguish a line of thinking that is ultimately characterised by possessing a degree of ontological awareness whilst persevering with a methodology that is inconsistent with this awareness; it is a line of thinking identified precisely by this ontological / 
methodological tension or inconsistency. Its practitioners recognise that social reality is a historical process of cumulative causation, but nevertheless continue to rely upon methods that require of reality that it conforms to given correlations, that render the science as still taxonomic" (Lawson, 2013:971)

Lawson updates this definition by translating it into the language of social ontology. Veblen's emphasis on taxonomy is identified with what Lawson calls deductivism, and thus with the methods of mathematical modelling. Veblen's conception of an 'evolutionary approach' is seen as equivalent to Lawson's preferred ontology which sees the social realm as a causal-processual open system. Thus, according to Lawson, neoclassical economists are:

"those who are aware (at some level) that social reality is of a causal-processual nature... who prioritise the goal of being realistic, and yet who fail themselves fully to recognise or to accept the limited scope for any overly taxonomic approach including, in particular, one that makes significant use of methods of mathematical deductive modelling."(Lawson, 2013:979)

Lawson's paper is concerned with the current state of economic theorising and brings forth two rather controversial consequences of this revised understanding of neoclassical economics:

1) That the term 'neoclassical' picks out a group of economists who do not share a common core or set of assumptions in terms of substantive theorising, but rather are joined by their failure to recognise a fundamental inconsistency between ontology and method in their work.

2) That many mathematically oriented, but self-defined heterodox economists could now be identified with this revised neoclassical category.

While this analysis raises a host of questions for the types of modern economic analysis, an important, consequence is to use Lawson's argument to clearly delineate the previously sketchy boundaries between neoclassical and mainstream economics. The defining feature of mainstream economic analysis is that it does not suffer from the 'neoclassical tension' attributed to neoclassical theorising because, to paraphrase Lawson, mainstream economists are those who are (a) wedded to mathematical deductivism as the all-consuming scientific method, and (b) regard all analysis that deviates from this stance as lacking knowledge-building content(Lawson, 2013:978) .

Our focus in the remainder of this paper engages directly with this distinction. Despite its controversial nature, we accept the fundamental plausibility of Lawson's redefinition of neoclassical economics as both coherent and consistent with the historical origins of term. However we believe that the redefinition of neoclassicism has consequences that go beyond the contemporary debate about the state of modern economics and indeed beyond the current opposition between heterodox and mainstream economists. An unintended consequence of this clearly defined distinction between mainstream and neoclassical economics is that it provides us with a new tool to investigate important questions in the history of economic thought. For example: what is the historical relationship between mainstream and neoclassical 
economics? If the mainstream emerged from neoclassical contributions, how and when did this transition occur?

In order to shed some light on these important questions, we have adapted an illustrative case study focussing on the genesis of the concept of moral hazard in the economics literature. Our argument, presented in sections three and four, is that the introduction of moral hazard in Arrow's seminal paper on healthcare bears all the hallmarks of Lawson's neoclassicism. These are: inconsistency between ontology and method; tension between a commitment to understand the phenomena and a commitment to modelling them in a particular way; a desire to understand the specificity of the system under investigation (healthcare), while respecting the formal constraints of the 'economic approach' to analysing social problems. This internal struggle was ignored by subsequent economists who saw the article simply as a progenitor of mainstream economic analysis, thus misunderstanding its neoclassical stance. However, in order to see how this break occurred we first revisit Arrow's seminal paper and give a reading of the article from this viewpoint.

\section{A reading of Arrow (1963)}

Arrow opens his article with: "This paper is an exploratory and tentative study of the specific differentia of medical care as the object of normative economics" (Arrow, 1963:941). This sentence encapsulates what Arrow attempts to do: to describe the provision of medical care in the USA during the early 1960s and discuss why this provision seems to be so far removed from the competitive market model. He explains the analytical findings of the competitive model, the two welfare theorems, and finishes by noting "if... the actual market differs significantly from the competitive model... the separation of allocative and distributional procedures becomes, in most cases, impossible" (Arrow, 1963:943). In this passage the tension characteristic of neoclassical contributions first appears: Arrow explicitly considers the distance between model and reality. If reality cannot be described in an accurate fashion by the paradigm, then it follows that questions about distribution and efficiency (what the mainstream would call positive and normative analysis), that formally arise in this literature, cannot be transferred to the real world.

The question of how to compare real life - the set of practical problems raised by the functioning of the healthcare ${ }^{1}$ system - with the competitive model presents a methodological problem for Arrow. He points out that the methodological controversy has raged for more than a century but acknowledges Friedman's well known instrumentalist argument as an influential contribution that claims to resolve the controversy by focussing solely on a model's ability to predict (Arrow, 1963:944). However, without giving a decisive argument against Friedman, Arrow rejects the

\footnotetext{
${ }^{1}$ For consistency with the rest of the paper we use throughout this section the term healthcare instead of medical care. It is important here to note that Arrow explicitly avoided the term healthcare in his original contribution, noting that his article is about the conditions of providing medical coverage to individuals. In his opening paragraph he stresses that there are many factors that influence health and medical coverage is only one of them, but that that is what he intends to investigate (Arrow, 1963:941). This may be seen as another example of the neoclassical tension in Arrow's article. Nevertheless, economists today use healthcare to denote this field of economic analysis, and for consistency we also follow this use.
} 
approach of focusing on price and quantity predictions as the only relevant data that can be used to test the competitive model. Instead, he investigates "the institutional organisation and observable mores of the medical profession" (Arrow, 1963:944). Here again we see clear evidence of the neoclassical tension: Arrow seeks to compare the model with a realistic account incorporating the socio-economic context rather than relying on a simplistic quantitative approach.

More specifically, he examines whether the preconditions for a competitive market system in medical care are actually met. These preconditions are: (1) existence of competitive equilibrium (2) marketability of all goods and services and (3) nonincreasing returns (Arrow, 1963:944). Marketability is identified as the main problem, and seen as a broader issue than the one analysed within the traditional externalities literature. Again, Arrow gives a very open and informal definition, writing "it will be sufficient to identify nonmarketability with the observed absence of markets" (Arrow, 1963:945) and focuses on two issues that create nonmarketability: risk and uncertainty. With risk he notes that while, due to illness and risk pooling, a well developed market should exist, it does not actually exist in practice (Arrow, 1963:945). As for uncertainty, he writes that with "uncertainty, information or knowledge becomes a commodity" (Arrow, 1963:946). In this context, it can be argued that Arrow sees information problems as related to environmental factors rather than only behavioural responses to stimuli. It follows that uncertainty is a natural hindrance to a well-functioning market. But when markets fail to operate, nonmarket institutions occasionally fill the existing gap, and in healthcare the government and other charitable institutions play this role. With this observation Arrow ends his extensive introduction and forges ahead with a survey of the healthcare market, focusing on the elements that distinguish it from the competitive model.

Arrows' survey focuses both on the supply and demand characteristics of the healthcare market. A recurrent theme in this section is the issue of trust and the existence of institutions and behaviour that lie outside the competitive model. Arrow describes the behaviour of physicians in detail, noting that there are very strong social and moral norms governing their behaviour. In order to illustrate this he explains that: "[a physician's] behaviour is supposed to be governed by a concern for a customer's welfare which would not be expected of a salesman" (Arrow, 1963:949). Divergence from the competitive model is not only restricted to the action of physicians. Arrow also speaks of the prevalence of non-profit hospitals, and even non-profit educational establishments training students to become doctors at subsidised cost. While profit seems to play a reduced role in the provision of healthcare, trust appears central. Patients trust doctors, non-profit hospitals and educational establishments that give accreditation. The patient-doctor relationship is extensively explored, and trust is important there in order to deal with the complex nature of medical care and the uncertainty of disease. Arrow notes a special aspect of this relationship, the "informational inequality" between doctors and patients, something both parties are aware of. Finally, he notes that there is some friction between competitive business practices and trust. Physicians are expected to: provide advice that is "completely divorced from self-interest"; treatment that responds to "objective needs" and not financial considerations; certificates that confirm the existence of illnesses truthfully and not to please customers (see Arrow, 1963:950). Thus, the physician is trusted not 
to abuse her special position by engaging in competitive practices that are both commonplace and arguably necessary in other markets.

Having provided this elaborate and realistic description of the healthcare market, Arrow proceeds to compare it with two versions of the competitive model, first under certainty, and then under uncertainty. When he considers the comparison with the competitive model under certainty ${ }^{2}$, he finds that there are four major departures: nonmarketability, increasing returns, entry requirements for physicians and price discrimination. The analysis generally follows well-established economic arguments that would have been familiar to the academic reader of the period. For example, he discusses problems of externalities, or how licencing laws restrict entry, or how price discrimination may be used to maximise profits for a collective monopoly. The neoclassical tension is once again clear in this discussion as he disagrees with the standard interpretation of price discrimination as simply maximising profits for the medical profession, and argues that the incidence of charity by the medical profession shows "the relevance and importance of social and ethical factors" (Arrow, 1963:957).

However, it is in the comparison of the medical market with the competitive model under uncertainty that Arrow breaks new ground. He starts his analysis by characterising optimal or ideal insurance, noting that when you have risk averse individuals, an actuarially fair or almost fair insurance scheme is welfare improving due to risk pooling. Drawing on standard methodological tools, he provides formal proofs (in an appendix) for this analytical result, which show that "the nonexistence of suitable insurance policies...implies a loss of welfare" (Arrow, 1963:959). But this analytical finding presents two puzzles: first, why should this be the case? And second, what is the scope for government action? Arrow writes: "It follows that the government should undertake insurance in those cases where this market, for whatever reason, has failed to emerge. Nevertheless, there are a number of significant practical limitations on the use of insurance" (Arrow, 1963:961). The discussion that follows is tentative and is obviously intended to be exploratory. In it, Arrow faces the consequences of the juxtaposition of his formal methodology and the reality of the American healthcare system. He attempts to blend abstract economic analysis of the theoretical problems associated with insurance in a market economy with empirical descriptions of actual gaps in insurance coverage.

It is in this discussion that Arrow introduces the problem of moral hazard. He writes: "one of the limits which has been much stressed in insurance literature is the effect of insurance on incentives. What is desired in the case of insurance is that the event against which insurance is taken be out of the control of the individual" (Arrow, 1963:961). Later on he notes: "It is frequently observed that widespread medical insurance increases the demand from medical care" (Arrow, 1963:961). Nevertheless, in these crucial pages moral hazard is not given a more exact definition, and, interestingly, the incentives problem noted en passant and quoted above is not formally explored. This is in contrast to the way Arrow discussed the ideal insurance case, where the analytical results were clearly presented in the text and formal proofs provided in the Appendix. Instead, in the case of moral hazard, Arrow gives a general

\footnotetext{
${ }^{2}$ He defines conditions of certainty as "consumers are presumed to be able to distinguish qualities of the commodities they buy." (Arrow, 1963:956)
} 
discussion noting that there are behavioural responses which may be relevant to his analysis. Rather than providing a formal framework to analyse these responses, he provides an illustrative example: if you insure your house against fire, then there is the issue of carelessness and even arson, and similar problems may also arise in medical insurance. He then notes that "to some extent the professional relationship between physician and patient limits the normal hazard in various forms of medical insurance" (Arrow, 1963:961), though this is far from a perfect check. Interestingly he argues that where there is scrutiny and control of payments by third parties (other than the doctor and patient) then this may be effective in reducing moral hazard. Furthermore, this may explain why, in some areas of healthcare, insurance policies are more widespread than others, as some activities like surgery are under third party supervision whereas others, like GP visits, are not.

In the last section of the paper Arrow is preoccupied with the problem of what happens when, due to the practical limitations discussed above, appropriate insurance markets do not, or have not, developed. He writes: "in the absence of ideal insurance, there arise institutions which offer some sort of substitute guarantees" (Arrow, 1963:965). This is because with uncertainty, "[the patient] would want some guarantee that the physician is using his knowledge to the best advantage. This leads to the setting up of a relationship of trust and confidence, one which the physician has a social obligation to live up to" (Arrow, 1963:965). This relationship of trust, that he observed when he was doing a survey of the medical care market in the previous section, is not incidental to the workings of that market, but instead serves an economic purpose - it fills a gap created by the problem of uncertainty. This nonmarket mechanism has its own rules that may actually further remove it from the competitive model. Arrow observes that "one consequence of such trust relations is that the physician cannot or at least cannot appear to act, as if he is maximizing his income at every moment in time" (Arrow, 1963:965). And again that "the very word, "profit" is a signal that denies the trust relations" (Arrow, 1963:965). Therefore trust is constitutive of the workings of the healthcare market, and it manifests itself across the key relationships that form the basis of the healthcare system: between patient and physician, in the certification and licencing of physicians by academic and other regulatory institutions, or even in the non-profit organisations that own and run hospitals.

In the conclusion Arrow clearly states that his analysis of the healthcare market has two significant implications for economic theory. First the observation that "the failure of the market to insure against uncertainties has created many social institutions in which the usual assumptions of the market are to some extent contradicted" (Arrow, 1963:967). There are a host of interpersonal relations that have economic importance and, these non-market relations create "guarantees of behaviour which would otherwise be afflicted with excessive uncertainty" (Arrow, 1963:967). Second this means that the competitive model has natural limits in its descriptive powers. It is an important part of the economic canon, but it cannot be the full picture, for there are other institutions in existence organised across fundamentally different lines. Taken in conjunction with the preceding discussion of healthcare, the conclusion of Arrow's paper stands out as a remarkably clear exemplar of what Lawson has called neoclassicism. There is an explicit avowal of the descriptive inadequacy of the standard economic paradigm, and of the existence of institutions that have developed and function in ways that are incompatible with it. This is a 
powerful indicator of the tension that persists between Arrow's concern to describe and understand socio-economic reality and the ontology imposed by standard techniques. There is also an equally explicit avowal of the limitations of the methodology of the competitive model as a tool. This is evident in his decision not to invoke a standard account in terms of event regularities in the analysis of moral hazard (as contrasted with the formal treatment of insurance in the appendix). The last line of the article provides an elegant summary of the neoclassical tension at work: "The logic and limitations of ideal competitive behaviour under uncertainty force us to recognize the incomplete description of reality supplied by the impersonal price system" (Arrow, 1963:967).

\section{Early reception: The first seven years}

Arrow's article received attention from the moment it was published. In fact, even when the article was still in proofs Arrow presented it in the 'secret' seminar in Cambridge, as he was visiting Cambridge for the academic year of 1963-4, ${ }^{3}$ which means that the article was becoming rapidly well known on both sides of the Atlantic. In the first seven years since its publication Arrow was cited 18 times in economics journals. These included one citation in the following journals: Review of Economics and Statistics (Feldstein, 1970), Quarterly Journal of Economics (Akerlof, 1970), American Journal of Agricultural Economics (Ball and Wilson, 1968), Journal of Law and Economics (Lees, 1962), the Journal of Business (Pashigian, Schkade et al., 1966), the Journal of Risk and Insurance (Pauly, 1970), the Journal of Human Resources. Three in Economica (Foldes, 1967; Williamson, Olson et al., 1967; Cotton, 1969). And finally eight in the American Economic Review (Arrow, 1965b; Boland, 1965; Lees and Rice, 1965; Diamond, 1967; 1968; Pauly, 1968; Crew, 1969; Newhouse, 1970). Of those eight, two where by Arrow in reply to published comments on his original paper. These early published comments and Arrow's replies constitute two distinct theoretical debates that set the scene for the subsequent interpretation and use of the article. There are substantial differences in what these two debates focused on, but also on how they relate to the transformation of economics and in particular the emergence of modern mainstream economic theorising.

The first citation of Arrow (1963) is by the British economist D. S. Lees (1962), in an article that analyses the UK National Health Service from a libertarian perspective. Lees argues that the basic problem of the NHS is not the nationalisation of the healthcare industry, but the abolition of prices for the services provided. This outcome makes healthcare a service outside what the market economy provides. The article continues by composing a list of arguments in favour of abolishing prices in medical care, and rebutting each in turn. One of the reasons tendered is that "medical care is "different" from other things that are normally bought and sold in markets"" (Lees, 1962:114). It is in relation to this objection that Lees references Arrow (1963) and writes that he finds the arguments in Arrow unconvincing. He concludes by saying that even if the government objective is to enforce equality of consumption of medical care, it does not follow that "a non-market situation, one in which there are no prices is inescapably necessary to achieve this purpose" (Lees, 1962:116). He goes on to

\footnotetext{
${ }^{3}$ This is noted by G.C. Harcourt who attended the seminar. Private correspondence with the authors.
} 
argue that this outcome can also be achieved through the market, and indeed this would be more compatible with how a free society works.

A second paper by Lees and Rice, (1965) is the first of the two comments published in the AER in response to Arrow's original paper. ${ }^{4}$ They start by quoting the following passage from Arrow: “...for present purposes, it will be sufficient to identify nonmarketability [of risk-bearing] with the observed absence of markets... It follows that the government should undertake insurance in those cases where this market, for whatever reason, has failed to emerge." (Arrow, 1963, pages 945, 961 quoted in Lees and Rice, 1965:141) They make the following two counterpoints to Arrow's claim: (1) due to buyer's and seller's costs, the absence of insurance policies for certain risks may be the optimal market response, not an inability of the market to develop, and (2) that it takes time for new types of insurance markets to emerge, but they do so eventually. The first point is formally explored, and shows that there may be optimal reasons for markets not emerging for some types of insurance. This argument is qualitatively different to the second one. There the authors argue that markets develop over time, as new needs create conditions for the emergence of products. They then suggest that since markets fill that gap in the long run, and since markets are assumed to be a desirable form of social organisation, then "whatever role government is to play in this transition, it would at least seem inappropriate to create permanent institutions to deal with what is essentially a temporary problem" (Lees and Rice, 1965:153).

Lees' libertarian position is implicit in both papers. He sees a fundamental antagonism between two types of social organisation - the market and the state - in which healthcare is a key battleground. His repeated critique of Arrow, despite its occasionally formalistic presentation, is firmly motivated by this normative perspective as he identifies Arrow as a defender of intervention in healthcare markets and hence, by proxy, a proponent of a state-sponsored healthcare system. Arrow's response to Lees effectively recognises the normative flavour of the debate, though he seeks to separate analytical claims from "normative implications". In the case of the former, he argues that not all institutional structures 'out there' can be analysed through the lens of market competition, citing a real world example to illustrate his point: "the Blue Cross-Blue Shield network is by no stretch of the imagination an example of a competitive market in health insurance. On the other hand, it would clearly be incorrect to regard it as a profit-maximizing monopoly. What has happened is a voluntary association has essentially played the role of a surrogate government" (Arrow, 1965b:156). What remains from this exchange is a genuine disagreement about the ability of the market system to deliver appropriate services in the healthcare sector. The debate of Lees and Rice vs. Arrow is ideologically charged, but it appears that the interlocutors understand that their disagreement is on personal values and competing systems of social organisation.

The second debate on Arrow's paper was with Mark Pauly, following a comment published in AER in 1968. Pauly starts by reviewing the exchange between Arrow and Lees and Rice, stating that there are actually better reasons than transaction costs

\footnotetext{
${ }^{4}$ There is also a contribution by Vincent Boland (1965), challenging some of the technical outcomes of the (Lees and Rice, 1965) comment, but his contribution is peripheral to our analysis here, other than an indication of how widely Arrow's original paper and subsequent comments were read by the academic community.
} 
for why "some insurances are not offered commercially" (Pauly, 1968:532). Pauly then turns to his main theme, the exploration of the problem of moral hazard, since, "in the controversy that followed [the exchange between Lees, Rice and Arrow] moral hazard seems to have been completely overlooked as an explanation of why certain types of expenses are not insured commercially" (Pauly, 1968:535 footnote 3). Furthermore, he argues that in the 1963 article, "Arrow appears to consider moral hazard as an imperfection, a defect of physical control...." or a "“"practical limitation" on the use of insurance which does not "alter the case for creation of a much wider class of insurance policies than now exist."'(Pauly, 1968:535 footnote 3). Instead Pauly presents moral hazard in a completely different light. He starts by offering a formal definition, which is that by lowering the marginal cost of care to the individual, you will increase usage of medical care. This behavioural response is not a characteristic of the personality of the individual, an aspect taken into account in the insurance literature 5 , but a rational reaction. He insists that "the response of seeking more medical care with insurance than in its absence is a result not of moral perfidy, but of rational economic behaviour" (Pauly, 1968:535). This choice of words can appear odd. What exactly does Pauly mean? Arrow when quoting this line by Pauly in his rejoinder adds "Mr. Pauly's wording suggests that "rational economic behaviour" and "moral perfidy" are mutually exclusive categories. No doubt Judas Iscariot turned a tidy profit from one of his transactions, but the usual judgement of his behaviour is not necessarily wrong" (Arrow, 1968:538).

This a core disagreement between the two theorists that deserves further analysis. By analogy, Pauly's argument may be recast in the following way: the fall of a large asteroid on planet earth that extinguishes all life is not the outcome of divine will, but simply the outcome of the laws of physics. By implication, any discussion of ethics in the situation of healthcare, is as irrelevant and 'un-scientific' as a discussion of theology in physics. A key disagreement, then, is whether human behaviour is completely determined by the axioms of rational choice in the same way that the law of gravity completely describes planetary movements. Here Pauly adopts the mainstream stance since he accepts the axiomatic straightjacket imposed by his formalisation of moral hazard. Arrow, on the other hand, is motivated by an attempt to understand the problems that might actually arise in healthcare insurance markets rather than those imposed by the structure of the model.

By accepting the logic behind this analogy we can analyse the rest of Pauly's argument in relation to moral hazard. If individuals are atomised and rational in the technical economic sense, and isolated from any cultural, ethical or social factors, then healthcare insurance faces the following problem. If the government decides to insure everyone against medical expenses, then the outcome is "to reduce the price charged to the individual at the point of service from the market price to zero" (Pauly, 1968:532). There is a subtle, but very important difference between Lees and Rice's argument that prices are abolished and Pauly's argument that prices are reduced to zero. According to Pauly, the government, by covering healthcare costs, sets a specific price for the good in what effectively remains a market system. This world, populated by isolated atoms whose behaviour is mechanically determined by implicit or explicit price signals, responds to institutional change only through the effect it has

\footnotetext{
${ }^{5}$ Pauly mentions reactions like 'hypochondria' and "outright fraud" as issues that concern insurance writers. (See Pauly, 1968:535)
} 
on the money denominated price of the good in question; the relevant event regularity in Lawson's terms. ${ }^{6}$

With a price of zero, the reader is lead to believe that demand will increase. The reason for this is because healthcare is treated like any other consumer good, with a possible range of demand elasticities. Pauly notes that if demand for healthcare goods is perfectly inelastic then moral hazard is not a problem, as demand would not increase with decreasing prices. It is interesting to observe here that Pauly is resting on very strong assumptions inherited from the competitive model: every economist knows that if the price of apples decreases people will buy more apples. But how does this translate in the real world market for medical care? In what way can consumers take advantage of the zero price? Will they undergo surgery when it is not medically necessary? Will they stay in hospital longer than required? Will they consume more pills or use more medical devices than they need? Or might they abuse their local GP privileges and clog waiting rooms? Pauly uses the visits to physician's office as an example of a situation when an "increase in use in response to a zero price would be relatively great" (Pauly, 1968:535). But he makes a broader point, and this is that when you have inelastic demand and uncertainty, (as is the case with surgery) then insurance is provided through the market already, as moral hazard would not be a problem. ${ }^{7}$

The outcome of this formalisation of the moral hazard is that when insurance should be provided it is already provided by the market. If it is not provided by the market, it can only be because the individual who purchases it has a tendency to overuse the services provided. Because the provider expects this rational reaction he charges more for the insurance than what is actuarially fair. But at these prices the individual finds it optimal not to buy insurance, as it is too expensive for the cover he needs. If the government provides this insurance and taxes the individual, the problem of overuse is still there, and the government substitutes one problem for another. Individuals will complain about high taxes to finance the system of provision and the solution will not be politically sustainable. After all, if they were willing to pay the cost of provision given the expectation of overuse the market would have provided the service without government intervention. Therefore, according to Pauly's analysis, government action is redundant and harmful in all situations.

This argument achieves an elegant transformation of the problem of market failure. It starts as in Arrow (1963) by presenting an ideal market in which appropriate insurance would exist if it was not for the adverse but rational behavioural response. This response gives rise to the actual market situation, in which optimality means that "some uncertain medical care expenses will not and should not be insured" (Pauly, 1968:537). It then measures any government intervention, either outright central provision or policies in the form of co-insurance and deductables against the

\footnotetext{
${ }^{6}$ Importantly, shame or other emotions are not taken into account, although even someone who is committed to developing and using this type of mechanistic frameworks of analysis may argue that this influences the implicit price of 'freely' provided healthcare, so that prices do not have to go exactly to zero.

${ }^{7}$ In this example Pauly is actually echoing what Arrow originally wrote in his 1963 article (see Arrow, 1963:962), where surgery is viewed as less subject to moral hazard than GP prescriptions are. However, this occurs for different reasons. Arrow stresses $3^{\text {rd }}$ party supervision during surgery, whereas Pauly stresses the elasticity of demand for the particular good.
} 
outcomes that the existing market can deliver, finding that no intervention, in this situation, can offer any improvement. By improvement what is meant here is very specific: moving closer to the idealised market represented by the competitive model in which the appropriate prices for the efficient provision of insurance exist.

In his rejoinder Arrow starts by briefly stating the analytical finding that Pauly presents, and agreeing with him that in such a situation optimality will not be achieved "either by the competitive system or by an attempt by the government to simulate a perfectly competitive system" (Arrow, 1968:537). But then he questions Pauly's "exclusive emphasis" on market incentives. He notes that insurance with rationing would solve the problem, and lists the following different ways rationing can take place:

"(1) there might be a detailed examination by the insurance company of individual cost items allowing those that are regarded "normal" and disallowing others, where normality means roughly what would have been bought in the absence of insurance; (2) they may rely on the professional ethics of physicians not to prescribe frivolously expensive cost of treatment, at least where the gain is primarily in comfort and luxury rather than in health improvements proper; (3) they may even, and this is not as absurd as Mr. Pauly seems to think, rely on the willingness of the individual to behave in accordance with some commonly accepted norms" (Arrow, 1968:538).

This list is an explicit avowal of the neoclassical tension apparent in Arrow's original paper. Whilst the first of the three reasons can be analysed within Pauly's narrow incentive framework, the following two cannot. Broader ethical and institutional factors that are drawn from observation and experience of the functioning of real healthcare services in society are the source of Arrow's critique. For Arrow shows the limits of this framework of analysis, as he writes: "the lesson of Mr. Pauly's paper is that the price system is intrinsically limited in scope by our inability to make factual distinctions needed for optimal pricing under uncertainty. Nonmarket controls, whether internalized as moral principles or externally imposed are to some extent essential for efficiency" (Arrow, 1968:538).

Unlike the previous debate, the Arrow vs. Pauly controversy cannot be analysed simply as an ideological disagreement, although they do occupy different sides of the ideological spectrum. A deeper philosophical divide separates the two authors, despite their reliance on a common technical toolbox to articulate their arguments. Pauly follows what was to become the standard mainstream approach by decontextualising the analytical framework and producing a model of moral hazard that is specifically defined, formally precise and highly portable between different real world applications. Arrow, on the other hand, refuses to ignore the complexity and openness of real healthcare systems when addressing problems of allocation and distribution. As a result the technical apparatus of modern economics can only take him so far and he recognises its weaknesses and limits when he faces them.

This exchange is also an early indication of the changes that would eventually lead to the dominance of a modern mainstream in which the scientific status of economics is judged purely on methodological grounds. This is evident in the disagreement between Arrow and Pauly on the relevance of ethics in the analysis of human conduct. In the coda of his response, Arrow writes "one of the characteristics of a successful 
economic system is that the relations of trust and confidence between principal and agent are sufficiently strong so that the agent will not cheat even though it may be "rational economic behaviour" to do so. The lack of such confidence has certainly been adduced by many writers as one cause of economic backwardness" (Arrow, 1968:538). Marshall - the archetypal neoclassical in both Veblen's and Lawson's terms - wrote the following in the first chapter of his Principles on the advances of modern society "...modern methods of trade imply habits of trustfulness on the one side and a power or resisting temptation and dishonesty on the other, which do not exist among a backward people....Adulteration and fraud in trade were rampart in the middle ages to an extent that is very astonishing, when we consider the difficulties of wrong-doing without detection at that time" (Marshall, 1891:18). Arrow and Marshall clearly share an ontological perspective that links economic behaviour to broader social processes and aims to extend beyond the limits imposed by their reliance on deductive techniques.

Pauly, in contradistinction was looking ahead to how economic theory was to develop in subsequent decades. He returned to healthcare markets in 1970, in an article that further developed the concept of moral hazard by analysing "different varieties" of this problem in healthcare and other types of insurance (Pauly, 1970). In this paper he finds that a price of zero creates all kinds of distortions in a market system, but notes that interventions that appropriately alter incentives may have a positive effect in the market. More importantly, 1970 is a watershed date for economic theory because it marks the publication of Akerlof's celebrated market for lemons article (Akerlof, 1970). Akerlof not only cites Arrow (1963) but starts his article by noting that "this paper presents a struggling attempt to give structure to the statement: "Business in underdeveloped countries is difficult"; in particular, a structure is given for determining the economic costs of dishonesty" (Akerlof, 1970:488). While this seems to be an allusion to the literature that Arrow was also pointing at in his response to Pauly, it becomes quickly apparent that the terms of the discussion have changed. The basic problem is one of information between different market participants, and Akerlof rigorously shows that asymmetries of information create all types of problems for efficient market interaction. Even dishonesty is treated in informational terms; if purchasers knew who the dishonest sellers are, there would be no inefficiencies in the market. In fact, Akerlof returns to the problem of public healthcare, and adds the following observation to the discussion Arrow vs. Pauly:

"He [Arrow] emphasizes "moral hazard" rather than "adverse selection". In the strict sense "moral hazard" is equally disadvantageous for both governmental and private programs; in its broader sense which includes "adverse selection", "moral hazard" gives a decided advantage to government insurance programs." (Akerlof, 1970:493)

Akerlof is ideologically on the same side as Arrow favouring government insurance programs. However, he uses Pauly's mainstream framework to make his argument and leaves behind him the neoclassical tension we located in Arrow (1963). The idealised market system in which informational problems do not exist is the measuring rod not only for any existing market, but also for any government intervention. What Pauly identified as a behavioural response - a 'rational reaction' by agents - thus received its final transformation and subsequent standardization into an informational problem. This pushed any discussion of social norms and their ethical underpinnings into the background, as economics established itself on new 
ground which encompassed the whole ideological spectrum by distancing it from real world problems.

\section{Becoming a Classic: The next 40 years}

Arrow's paper on medical care is one of the most heavily cited papers ever published by the American Economic Review. As an indication of its success, it has 1,528 articles citing it in the web of science core collection and more than 6,000 in Google scholar (search on 6/02/2015). It was also chosen as one of the 20 most important articles published in AER in its first 100 years. Furthermore, it has not only became a key text in economic theory, but it is also widely cited by academics and policymakers in a number of other fields, including law, sociology, political science, health policy and insurance. In fact, as Mark Peterson shows, whilst in the first decade of its publication it held greater significance for economists, by the 1990s it had became a focus of attention for non-economists as well (Peterson, 2001:825).

The neoclassical tension apparent throughout the paper explains both its early success within economics and its enduring influence in the other social sciences and policy circles. It is beyond the scope of this section to describe the whole interdisciplinary literature that follows Arrow's (1963) article. Surveys on the impact of Arrow's article in a variety of fields can be found in Vol. 25 No. 5 of the Journal of Health Politics, Policy and Law published in October 2001. There an array of articles by leading scholars in their fields are joined with a forward by Mark Pauly, and a postscript by Arrow, giving a more complete view of the impact Arrow's article had across disciplines including economics in its first 40 years since publication. However, for our purposes, it is sufficient to point out that whilst social scientists who were unhampered by the ontological limitations of the economic method took a variety of different messages from Arrow's article, the economic use of his arguments has been much more limited.

Arrow is generally seen as providing a pioneering and influential analysis of healthcare, but amongst economists he is generally cited as the source of the modern conceptualisation of a type of market failure. In this context, his introduction of the idea of moral hazard has been extremely influential, and it is as a forerunner of the moral hazard and asymmetric information literature that the article is principally remembered in mainstream economics today. ${ }^{8}$ In other words, it is principally Pauly's interpretation of Arrow's paper that has dominated economics. The neoclassical tension that Arrow clearly struggled with when beginning the economic analysis of healthcare has been set aside. Instead Arrow's paper is now seen as a necessary but incremental stage in the 'progressive' mainstream project of transforming health economics into a formal subfield populated by microeconomic models of asymmetric information. The committee that chose the top twenty articles ever published in the $A E R$ makes this last point explicitly:

\footnotetext{
${ }^{8}$ But not exclusively. For example Newhouse's (1970) frequently cited article deals with a theory of non-profit institutions, by presenting an economic model of a hospital and this follows one of the insights found in Arrow (1963). But on the whole, it is safe to say that these other strands of research are nowhere near in volume and influence in comparison to the moral hazard literature.
} 
"This paper provided a framework for thinking about the economics of the market for medical care using the language and tools of modern microeconomics. It argued that the aforementioned market is beset by market failures because consumers are exposed to risks that are not fully insurable (in large part due to problems of moral hazard), and because they lack the information and expertise required to assess risks and treatments. It hypothesized that various salient features of the institutions governing the provision of medical care are best understood as social adaptations aimed at redressing the resulting inefficiencies. It also noted that in some cases those institutional adaptations undermine competition and perversely contribute to inefficiency. Though written well prior to the emergence of the formal literature on asymmetric information, the paper anticipated many of the central issues that continue to occupy health economists today." (Arrow, Bernheim et al., 2011:2)

A more eclectic and partial way to see how the paper entered the canon of mainstream economics is to observe that it has been cited in three Nobel laureate lectures, those of Kenneth Arrow, James Mirlees and Joseph Stiglitz. This, in itself, is remarkable enough, as none of these Nobel prizes where particularly related to developments in the healthcare market. However, in all three cases it is the wider ramifications of the abstract findings of the paper that make it key in the literature that these lectures survey. First Kenneth Arrow himself mentioned the paper in his 1972 lecture, when discussing general equilibrium and uncertainty, noting that 'moral hazard' is a problem when you have unobservable behaviour and insurance. He then writes: "I would hold that the allocational difficulties arising from the inequality in information are of importance in such diverse fields as medical care and racial discrimination" (Arrow, 1974:269) before referring to the (1963) article. Then, James Mirlees in 1996 devotes a section of his lecture on moral hazard, and after defining the concept notes "Medical care has been regarded as a prime example in the economics literature, perhaps surprisingly" (Mirrlees, 1997:1323) before referring both to Arrow (1963) and Pauly (1968). Finally, Joseph Stiglitz devotes a section of his lecture on 'Sharecropping and the General Theory of incentives', arguing that with imperfect information, people's incentives became a problem. Therefore, "the adverse effect of insurance on incentives to avoid the insured-against contingency is referred to as moral hazard" (Stiglitz, 2002:465). In a footnote he notes that the concept comes from insurance literature and adds "Not taking appropriate care [when having insurance] was thought to be "immoral"; hence the name" (Stiglitz, 2002:465 footnote 10) before referring to Arrow's work (Arrow, 1963; 1965a) as an important precursor for the literature on moral hazard that followed.

This short history illuminates how mainstream economics integrated Arrow's work with developments in economic theory over the next 50 years. Pauly in his forward of a special issue of the Journal of Health Politics, Policy and Law, celebrating in 2001 almost 40 years of Arrow's article, eloquently writes "The introduction to health economics of the topic of moral hazard ignited a firestorm of interest in the impact of insurance on the process of care, with both theoretical and empirical dimensions. The major empirical topic was the measurement of the extent of moral hazard, and the major theoretical question was how that magnitude would affect the ideal design of an insurance policy that relied on patient cost-sharing to limit medical spending" (Pauly, 2001:830). This research agenda persists to this day as economists continue to explore the empirical and theoretical complications of the problem of incentives in markets 
with different varieties of imperfect information (See e.g. Einav, Finkelstein et al., 2013).

\section{Conclusion}

We began our argument by noting that Tony Lawson's reinterpretation of neoclassicism provides much needed clarity to the discussion about what neoclassical economics is and how and when we should use the term. This clarity comes at a price insofar as the critique of modern economic theorising is concerned, because it would essentially define neoclassicism through its deficiencies and hence it could be seen as an attempt to pathologise neoclassical economists. As Lawson notes, it would also necessarily lead to the reclassification of many heterodox economists as 'neoclassical'. In this paper we have set aside these concerns without wishing to deny their importance. This is because we intended to explore an under-researched corollary of Lawson's argument. When applied to question of the transformation of economic thought in the $20^{\text {th }}$ century, Lawson's revised conception of neoclassicism has important uses and yields novel insights. Our example, drawing on the history of healthcare economics, seeks to illustrate this. Firstly, we have demonstrated that interpreting Arrow's 1963 paper as suffering from 'neoclassical tension' is crucial to understanding the debates that emerged after it was published, but also important in placing this contribution in the canon of neoclassical theory that preceded it. Secondly, we have shown that by mapping the key differences between mainstream economics and neoclassicism we can similarly illuminate our understanding of the appropriation, formalisation and development of Arrow's ideas by subsequent theorists Thus we demonstrate that this distinction can be used to analyse an important chapter in the history of economic analysis, the post-war transition from neoclassical theory to mainstream model building

\section{References}

Akerlof, G. A. (1970). "The Market for "Lemons": Quality Uncertainty and the Market Mechanism." The Quarterly Journal of Economics 84(3): 488-500.

Arrow, K. J. (1963). "Uncertainty and the Welfare Economics of Medical Care." The American Economic Review 53(5): 941-973.

Arrow, K. J. (1965a). Aspects of the theory of risk-bearing (Yrjo Jahnsson lectures). Helsinki, Finland, Yrjo Jahnssonin Saatio.

Arrow, K. J. (1965b). "Uncertainty and the Welfare Economics of Medical Care: Reply (The Implications of Transaction Costs and Adjustment Lags)." The American Economic Review 55(1/2): 154-158.

Arrow, K. J. (1968). "The Economics of Moral Hazard: Further Comment." The American Economic Review 58(3): 537-539.

Arrow, K. J. (1974). "General Economic Equilibrium: Purpose, Analytic Techniques, Collective Choice." The American Economic Review 64(3): 253-272.

Arrow, K. J., B. D. Bernheim, et al. (2011). "100 Years of the "American Economic Review": The Top 20 Articles." The American Economic Review 101(1): 1-8.

Ball, D. S. and J. W. Wilson (1968). "Community Health Facilities and Services: The Manpower Dimensions." American Journal of Agricultural Economics 50(5): 1208-1222. 
Boland, V. F. (1965). "Uncertainty and the Welfare Economics of Medical Care: Comment." The American Economic Review 55(5): 1172-1173.

Cotton, M. L. (1969). "Medical Care and the Economics of Sharing." Economica 36(144): 351-362.

Crew, M. (1969). "Coinsurance and the Welfare Economics of Medical Care." The American Economic Review 59(5): 906-908.

Diamond, P. A. (1967). "The Role of a Stock Market in a General Equilibrium Model with Technological Uncertainty." The American Economic Review 57(4): 759-776.

Einav, L., A. Finkelstein, et al. (2013). "Selection on Moral Hazard in Health Insurance." The American Economic Review 103(1): 178-219.

Feldstein, M. S. (1970). "The Rising Price of Physician's Services." The Review of Economics and Statistics 52(2): 121-133.

Foldes, L. (1967). "Income Redistribution in Money and in Kind." Economica 34(133): 30-41.

Latsis, J. and C. Repapis (2014). "A model intervenes: the many faces of moral hazard." Cambridge Journal of Economics 38(4): 743-760.

Lawson, T. (2013). "What is this 'school' called neoclassical economics?" Cambridge Journal of Economics 37(5): 947-983.

Lees, D. S. (1962). "The Logic of the British National Health Service." Journal of Law and Economics 5(ArticleType: research-article / Full publication date: Oct., 1962 / Copyright (C) 1962 The University of Chicago): 111-118.

Lees, D. S. and R. G. Rice (1965). "Uncertainty and the Welfare Economics of Medical Care: Comment." The American Economic Review 55(1/2): 140-154.

Marshall, A. (1891). Principles of Economics. London, Macmillan.

Mirrlees, J. A. (1997). "Information and Incentives: The Economics of Carrots and Sticks." The Economic Journal 107(444): 1311-1329.

Newhouse, J. P. (1970). "Toward a Theory of Nonprofit Institutions: An Economic Model of a Hospital." The American Economic Review 60(1): 64-74.

Pashigian, B. P., L. L. Schkade, et al. (1966). "The Selection of an Optimal Deductible for a Given Insurance Policy." The Journal of Business 39(1): 3544.

Pauly, M. (2001). "Forward." journal of Health Politics, Policy and Law 26(5): 829834.

Pauly, M. V. (1968). "The Economics of Moral Hazard: Comment." The American Economic Review 58(3): 531-537.

Pauly, M. V. (1970). "The Welfare Economics of Community Rating." The Journal of Risk and Insurance 37(3): 407-418.

Peterson, M. A. (2001). "Kenneth Arrow and the Changing Economics of Health Care." journal of Health Politics, Policy and Law 26(5): 823-828.

Stiglitz, J. E. (2002). "Information and the Change in the Paradigm in Economics." The American Economic Review 92(3): 460-501.

Williamson, O. E., D. G. Olson, et al. (1967). "Externalities, Insurance, and Disability Analysis." Economica 34(135): 235-253. 